\title{
Reflexões sobre 0 envelhecimento e bem-estar de idosas institucionalizadas
}

\author{
Reflections on ageing and well-being of institutionalized elderly women
}

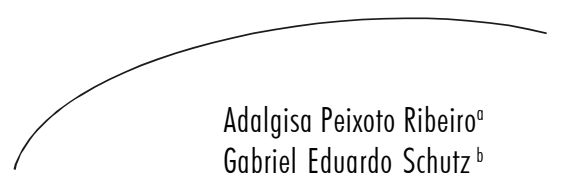

\section{Resumo}

Este trabalho tem o objetivo de estabelecer similitudes e discrepâncias entre os discursos sobre o próprio bem-estar, produzido por dois grupos de idosas viúvas de origem rural, em asilo e em convívio com a família na cidade de Caratinga, Minas Gerais. Foram entrevistadas oito idosas, sendo quatro institucionalizadas e quatro da comunidade. Foram comparadas as idéias centrais e as ancoragens contidas nos discursos. Os resultados mostram que as institucionalizadas atribuem ao trabalho o sentido da vida, as interações sociais estão ausentes em seus discursos, a doença recebe outra conotação, o cuidado à saúde não ocorre de forma autônoma e a presença das questões culturais, como a religiosidade, é marcante entre elas. Concluímos que a institucionalização imprime nas idosas uma representação diferenciada em relação a seu próprio bem-estar. As questões que caracterizam o envelhecimento como uma fase de perdas, solidão e dependência estão presentes com maior intensidade entre as idosas que vivem na instituição asilar.
Palavras-chave: envelhecimento; viuvez; mulheres; instituição de longa permanência para idosos; felicidade

\section{Abstract}

This paper aims to establish similarities and discrepancies between the speech on their own well-being, in two groups of elderly widows of rural origin, in asylum and living with their family in the city of Caratinga, state of Minas Gerais. Eight women were interviewed, four institutionalized and four in the community. The central ideas in their speeches were compared. Results showed

Correspondência / Correspondence

Adalgisa Peixoto Ribeiro

R. Cosme Velho, 98 - Cosme Velho

22241-090 - Rio de Janeiro, RJ, Brasil

E-mail: adalpeixoto@yahoo.com.br 
that the elderly institutionalized widows consider work the meaning of their lives; the social interchange is absent from their speech; illness acquires another connotation; healthcare is not autonomous; and the presence of cultural issues, such as religiosity, is strong among them. We concluded that institutionalization gives those elderly women a different representation in relation to their own welfare. The issues that characterize ageing as a phase of losses, solitude and dependency are more intense among the elderly women who live in asylums.
Key words: aging; widowhood; women; homes for aged;

happiness

\section{INTRODUÇÃOO}

A questão do envelhecimento demográfico e sua rápida ocorrência nos levam a uma preocupação acerca das condições de vida dos idosos como população vulnerável em termos de bem-estar (físico, psíquico e social).

O envelhecimento humano é um processo que ocorre mergulhado em um contexto histórico e cultural. Cada indivíduo apresenta características singulares marcadas por sua história de vida e pelas experiências acumuladas ao longo de sua existência. Para Assis, ${ }^{1}$ o declínio biológico normal que acontece com o envelhecimento, o aparecimento de doenças e dificuldades funcionais sustentam a concepção de velhice como um período de decadência inexorável.

No imaginário social, o envelhecimento é um processo que está relacionado com a marcação da idade como algo natural e que se processa como desgaste, limitações, perdas físicas e de papéis sociais terminando com a morte. ${ }^{2}$ Apesar disso, as pessoas experienciam o envelhecimento de forma diferenciada.

Envelhecer em determinado grupo social é uma experiência carregada de características próprias desse grupo. Nos idosos que vivem em comunidades rurais, e principalmente nas mulheres, podemos observar um forte envolvimento na rede de suporte social de família, amigos e vizinhos. Outro fato que marca a existência dessas pessoas é a centralidade das relações familiares e os valores de autonomia e independência. ${ }^{3}$

Quando a pessoa está inserida na família, as relações e as trocas que ocorrem nesse ambiente e em ações na comunidade são enriquecedoras, principalmente para os idosos. Apesar das transformações pelas quais passam a família, a casa ainda é um local que oferece o calor necessário para o desenvolvimento da vida.

Viver de forma livre, na comunidade pressupõe a existência de uma rede social ampla e uma vivência mais tranqüila das transformações advindas com o processo de envelhecer.

Sendo o envelhecimento influenciado por aspectos externos, a vivência desse processo em contexto como uma instituição asilar pode ser profundamente marcada por características comuns a uma realidade que preza pelo coletivo, em detrimento da individualidade do idoso. 
O asilo é a modalidade mais antiga de atendimento ao idoso fora de seu convívio familiar, tendo como conseqüência o isolamento, a inatividade física e mental e, por fim, uma redução na qualidade de vida. ${ }^{4} \mathrm{~A}$ institucionalização, porém, é uma realidade que está sofrendo uma demanda cada vez maior, por fatores demográficos, sociais e de saúde. ${ }^{5}$

Diante da possibilidade de alienação e falta de perspectiva ${ }^{6}$ da pessoa idosa que vive numa instituição de longa permanência, podemos questionar a respeito de sua vivência da velhice e de seu bem-estar. A experiência do envelhecimento de idosos de origem rural no contexto asilar é permeada de contradições e quebra de valores tidos como fundamentais na existência dessas pessoas.

Muitos autores têm tomado o envelhecimento e a saúde do idoso como objeto de estudo, procedendo a uma descrição exterior, ou seja, o idoso é descrito pelo outro. Beauvoir ${ }^{7}$ afirma que o idoso é um indivíduo que "interioriza a própria situação e a ela reage". Com base nessa perspectiva e na Organização Mundial de Saúde (OMS), que define saúde como o bem-estar físico, mental e social, e não só ausência de doença, nos deparamos com a necessidade de refletir sobre o envelhecimento e o bem-estar da pessoa idosa através de seu próprio olhar.

Sabemos que o envelhecimento e o "bemestar" apresentam vários impactos no ser humano, e neste estudo não pretendemos esgotar o assunto, mas seguir um caminho que nos permita olhar esse processo com os olhos de quem o está vivenciando.
O objetivo deste trabalho é estabelecer similitudes e discrepâncias entre os discursos sobre o próprio bem-estar, produzido por dois grupos de idosas de origem rural - em asilo e em convívio com a família - na cidade de Caratinga, Minas Gerais. Também objetivamos analisar as diferenças na percepção sobre o próprio bem-estar de idosas institucionalizadas e não-institucionalizadas, e comparar os resultados obtidos com as reflexões sobre o envelhecimento existentes na literatura que aborda o tema dos efeitos da institucionalização sobre o bem-estar do idoso.

\section{MATERIAIS E MÉTODOS}

Este trabalho utilizou uma abordagem qualitativa. Inicialmente, realizou-se uma entrevista semi-estruturada com dois grupos de idosas provenientes de áreas rurais. Participaram da pesquisa oito pessoas, quatro delas vivendo numa instituição de longa permanência, localizada no município de Caratinga, Minas Gerais e outras quatro em convívio com a familia, escolhidas aleatoriamente num bairro da periferia da cidade, para posterior análise de conteúdo e interpretação dos resultados obtidos.

Os discursos levantados nas entrevistas foram transcritos literalmente e, posteriormente, foram identificadas as idéias centrais relacionadas à percepção do próprio bem-estar de conteúdo semelhante. Finalmente, comparamos as idéias centrais contidas nos discursos produzidos pelos dois grupos de idosas estudados, visando a estabelecer similitudes e discrepâncias entre eles. 
As entrevistas foram realizadas mediante um consentimento livre e esclarecido. A aprovação do Comitê de Ética em Pesquisa da Escola Nacional de Saúde Pública foi obtida para a realização do trabalho.

\section{RESULTADOS E DISCUSSÃO}

Analisando os discursos das idosas, pudemos encontrar alguns aspectos que caracterizam os dois grupos e, principalmente, o grupo das institucionalizadas e sua vivência no ambiente asilar. Foram identificados pontos de grande relevância nas falas das idosas entrevistadas e que serão apresentados a seguir, juntamente com alguns trechos dos discursos que os exemplificam.

A primeira questão diz respeito ao trabalho e como as idosas institucionalizadas percebem sua ausência ou incapacidade para realizá-lo. Ocorre uma desvalorização pessoal, por não realizarem atividades produtivas.

Alguns autores afirmam que, entre os idosos, o sentimento de ser útil é essencial para a visão positiva de si mesmo, ${ }^{8}$ é um meio de realização e valorização pessoal e social do indivíduo. Alguns valores como o trabalho, a autonomia e a independência são extremamente importantes para as pessoas idosas e ajudam a moldar a identidade e a história de vida. ${ }^{3} \mathrm{O}$ valor socialmente reconhecido do trabalho garante a ele um lugar de destaque na vida do ser humano. Ele aparece como aquilo que foi uma das principais habilidades que, pela diminuição das capacidades físicas e conseqüente lentidão na execução das ativi- dades diárias, coloca o idoso num segundo plano quanto à vida social. ${ }^{9}$

As participantes representam sua situação atual como a perda do papel social de trabalhadoras e cuidadoras do lar. A noção da perda da capacidade de trabalho apresenta-se também sob a forma de comparação com o tempo da juventude.

As idosas se sentem inúteis e lamentam não mais poder trabalhar. Isto se torna claro quando analisamos alguns trechos como o seguinte:

"Eu agora num tô fazendo bem dizer nada. Eu num tô valendo nada... Mas eu faria, quando eu tava mais nova, com mais saúde. Fazia serviço de casa, lavava roupinha minha e fazia as coisas. E quando eu tava mais nova eu trabalhava na roca, plantava as coisas, ajudava meu pai colher, né. É desse jeito a vida, né." (Idosa institucionalizada, 88 anos).

A ausência do trabalho coloca as idosas numa situação de falta do que fazer e, a partir de então, não conseguem encontrar outras atividades que possam preencher o vazio deixado pela ruptura existente entre o passado produtivo e o presente situado na ociosidade de uma instituição.

Para Herédia ${ }^{10} \mathrm{O}$ indivíduo idoso que passa pela última fase do ciclo vital sem perspectivas de futuro e de vida, sente ainda mais agravado seu estado, por não saber o que fazer de seus dias, por estar sempre entre o aborrecido e o melancólico, o que o leva muitas vezes à dependência e ao alheamento. Esta ociosidade leva as idosas a uma posição passiva 
diante da vida, que transcorre como se fosse algo externo e alheio à sua existência.

"Nada, nada. Eu só vivo sentada, só sentada aqui penando. Dia inteiro eu fico de castigo. Só almogo, janto, deito e amolo os outros." (Idosa institucionalizada, 71 anos).

Entre as pessoas acima de 60 anos, as percepções das perdas, das incapacidades e das doenças são aspectos salientes das representações da velhice. ${ }^{9}$

É importante ressaltar que, em sua maioria, as idosas institucionalizadas apresentaram dependência para a locomoção, o que restringe em parte suas possibilidades de realização de algum trabalho doméstico na instituição. Os trabalhos manuais e as atividades religiosas realizam a função de evitar a inatividade total.

"Eu faço esses trabalhos de bordar e rezar terço." (Idosa institucionalizada, 71 anos). "Eu faço esse tapete aqui, faço mais nada, como é que eu posso fazer, num tem jeito, coitada de mim..." (Idosa institucionalizada, 76 anos).

As idosas institucionalizadas somente conseguem ver as atividades produtivas, tais como as tarefas domésticas e as que são realizadas na roça, como as únicas possíveis. As possibilidades de outras ocupações parecem não existir e as atividades sociais estão ausentes em seus discursos.

Aqui podemos apontar uma segunda questão, que está relacionada à solidão e à falta do outro entre as idosas que residem na instituição. As idosas asilares relatam não receberem visitas de familiares e ocasionalmente de pessoas estranhas que vão à instituição para visitas coletivas.

Em contrapartida, as idosas que vivem na comunidade apresentam, em suas falas, a presença de interações com outras pessoas. As relações sociais aqui parecem existir com grande intensidade, como podemos identificar nas falas destacadas a seguir:

"Faço visita ali no Josino mais a Figena, levo o tempo conversando com eles lá. Distraindo eles também, né. (Idosa da comunidade, 70 anos)".

"Trabalho na minha casa, lavo roupa, arranjo casa, olhar menino pirracento, quebro o galho dos vizizinhos, é isso mesmo... Assisto televisão, fico à toa. A hora que num tiver à toa vou pra casa dos viz̨inhos, faço minha comidinba e esses dia to levando almoco pro meu neto. E cuido de uma senhora doente." (Idosa da comunidade, 66 anos).

Em alguns trabalhos, como o de Dorfman et al., ${ }^{3}$ com idosos de comunidades rurais, foi encontrado um vínculo entre os habitantes do local, através das memórias de idosos que participaram integralmente da vida da comunidade, não somente nas igrejas, mas também nas atividades de suporte social. As pessoas que mantêm relações sociais favorecem seu bemestar físico, psicológico e social. ${ }^{11,12,13}$

A presença das interações com o outro parecem contribuir para um melhor enfrentamento das situações adversas que podem surgir no cotidiano das pessoas. $\mathrm{O}$ apoio social é um fator que contribui na manutenção 
da saúde em momentos de estresse,${ }^{14}$ ajudando na superação de acontecimentos como a morte de alguém da família, a perda da capacidade de trabalho ou mesmo a institucionalização.

As idosas institucionalizadas de nosso estudo não apresentam essa possibilidade de ajuda para a vivência de situações conflituosas que provavelmente são constantes quando se vive em ambiente asilar. As trocas afetivas que possibilitam a partilha de sofrimentos, tristezas, preocupações e alegrias não estão presentes em suas falas.

A idéia de abandono é mais marcante que a importância atual ou passada da idosa para a família. O abandono, no caso das idosas de nosso estudo, não é enunciado como tal, mas é perceptível através dos discursos apresentados por elas. Isto acontece sobretudo quando a pessoa perde parcialmente sua família, como nos casos de institucionalização.?

A situação de estar sozinha, ou seja, sem a companhia de algum familiar e principalmente a perda do marido, traz à tona o sentimento de solidão. Com a morte do cônjuge, a familia primária da idosa se desfaz, o que qualifica essa fase da vida como solitária e triste.?

Quando o idoso não vive mais no seio da família, ocorre um rompimento do equilíbrio das funções familiares de oferecer pertencimento e favorecer a individualidade, provocando sentimentos de tristeza, desamparo, desprezo, solidão e abandono. ${ }^{10} \mathrm{O}$ trecho a seguir retrata de forma clara a presença do sentimento de abandono:
"Eu num gosto é de ficar aqui, fico porque en sô obrigada num tem onde ir." (Idosa institucionalizada, 71 anos).

Outro ponto significativo no discurso das idosas está ligado às questões relativas à saúde e a doença. As idosas representam a doença como aquilo que as impede de trabalhar. Mais uma vez, o trabalho aparece como algo que dá significado à existência humana. Sua importância na vida das idosas entrevistadas é muito clara em suas respostas. Neste sentido, só pode realizar algum trabalho quem tem saúde.

"... coitada de mim eu já fiz muito, minha filha, mas se eu tivesse boa da minhas perna, ah minha fia, en fazia de tudo, igual eu fazia."(Idosa institucionalizada, 76 anos).

"Tô com disposição pra mim andar, pra mim passear, num é. Mais disposição pra trabathar en tenho." (Idosa da comunidade, 77 anos).

Através da fala das idosas, podemos identificar que o conceito de saúde da Organização Mundial da Saúde se aplica de forma muito clara a essas idosas institucionalizadas. Quando perguntadas a respeito da presença de alguma doença, as respostas foram, na maioria das vezes, negativas, mas logo após a descrição de alguma seqüela ou alguma entidade patológica vinha à tona. Neste sentido, as doenças como diabetes e pressão alta parecem ter outra conotação e nem parecem doenças:

"Num tô (doente). Parkison. Só isso que ele (o médico) falou que eu tenho." (Idosa da comunidade, 79 anos). 
"Não... que eu tenho épressão alta, né. Faço tratamento da pressão alta." (Idosa da comunidade, 77 anos).

"Eu não. Só eu sinto dor nos meus nervos. Onde tem nervo em mim dói. Onde tem nervo dói. Tudo enquanto é lugar dói."(Idosa institucionalizada, 71 anos).

O envelhecimento é marcado por aspectos positivos de sabedoria, consciência da finitude, esperança e também por perdas que podem gerar sentimentos de solidão, desvalorização pessoal e profissional, e podem até levar à dependência e à falta de autonomia. ${ }^{10}$

Entre as idosas institucionalizadas, não aparece um discurso autônomo em relação ao cuidado com a saúde, o que é delegado à instituição onde residem. Esta pode ser interpretada como uma atitude passiva frente ao cuidado da própria saúde ou, por outro lado, pode revelar uma estratégia da instituição para atender aos idosos e garantir que eles tomem seus medicamentos em horários previstos e, principalmente, não interrompam o tratamento. Esta situação de controle dos medicamentos por parte da instituição também foi encontrada no estudo de Herédia et al.. ${ }^{10}$

É evidente que, além de variáveis como idade e sexo, a situação civil das idosas e moradia atual influenciam os papéis sociais, realização de atividades consideradas importantes pelas idosas, no cuidado com a saúde e nas interações sociais, por definirem condições de vida que limitam o desenvolvimento de tais atividades.
"Eles me dão remédio de manhã e de noite. Eu num guardo na cabeça o nome dos remédios não. Sei que épor causa de pressão. Eu tem problema de pressão alta." (Idosa institucionalizada, 71 anos).

Finalmente, uma questão muito significativa levantada nos discursos produzidos pelas mulheres idosas abordadas foram as questões culturais. Constatamos que as falas estavam impregnadas de valores e experiências adquiridas ao longo da vida de cada uma e que marcam profundamente a maneira de entender e perceber as coisas.

Segundo Rodrigues et al. ${ }^{15}$ para se entender o "estado de envelhecimento de cada um", devese levar em conta os valores, as atitudes e as crenças dos idosos. Diante da "pluralidade de experiências individuais", o pesquisador que estuda o envelhecimento tem a "possibilidade de confrontar as diferentes experiencias de envelhecimento uma com as outras, e a tentativa de identificar as constantes" ${ }^{16}$

Questões culturais como a religiosidade estão presentes nos discursos das idosas que se colocam de forma passiva e conformista diante da saúde e da doença, que são dados por Deus sem nenhuma influência delas.

Fatores sociais e culturais desempenham função importante nas percepções e expectativas das pessoas e de como elas vêem sua saúde e qualidade de vida. ${ }^{17}$

A religiosidade parece desempenhar papel importante no enfrentamento das situações de conflito vividas na velhice, facilitando a aceitação das perdas, o enfrentamento de 
situações estressantes e as dificuldades da vida. Apresenta um significado social e certa eficácia diante dos problemas e dificuldades enfrentadas diariamente. ${ }^{18}$

A espiritualidade depende de componentes como a necessidade de encontrar significado, razão e preenchimento na vida; a necessidade de esperança e vontade para viver; a necessidade de ter fé em si mesmo, nos outros ou em Deus. ${ }^{19} \mathrm{O}$ significado é uma necessidade considerada essencial à vida e, quando uma pessoa se sente incapaz de encontrá-lo, sofre em função da presença de sentimentos como vazio e desespero.

Para Elkins, citado por Freire Jr, ${ }^{20}$ “ a espiritualidade é a habilidade de enxergar o sagrado nos fatos comuns, tendo a consciência de uma dimensão transcendente, que leva em consideração o próprio ser, os outros, a natureza e a vida".

As idosas institucionalizadas, como também as residentes na comunidade, se referem à saúde como algo transcendente, ou seja, ela é estabelecida por Deus e, desta forma, está fora de seu controle:

"Deuspois assim né, que fazer, né. Deus quer assim o que vai fazer, né." (Idosa institucionalizada, 71 anos).

"Deus ainda tá me dando esse muncadinho (de saúde)."(Idosa institucionalizada, 76 anos).

"Num posso clamarporque Deus sabe o que faz.pra gente..." (Idosa institucionalizada, 88 anos).
"O que Deus dá nós tem que está satisfeita, né." (Idosa institucionalizada, 71 anos).

A fé oferece um sentido à vida e consolo ante as situações de angústia e incerteza, oferece esperanças e ajuda a enfrentar as experiências mais dramáticas do cotidiano, possibilitando uma adaptação à situação vivenciada no momento presente. ${ }^{21}$ As explicações religiosas sobre saúde/doença se apresentam de diferentes formas e têm raízes históricas profundas, mantendo-se nas representações sociais dos indivíduos e ocupando lugar de destaque em seus discursos. ${ }^{22}$

Durante as entrevistas observamos, através das respostas, que o envelhecimento e o próprio sentido de saúde e satisfação estão intimamente relacionados com a experiência e a história de vida de cada uma. A satisfação com a saúde que hoje apresentam depende daquilo que conseguem realizar:

"Eles tudo fala comigo, que en devo tá satisfeita, por que tô andando, tô conversando, num tô mal de cama." (Idosa institucionalizada, 88 anos).

"Dia que resolvo eu saio, ando pra toda banda, vou e volto, graças a Deus." (Idosa da comunidade, 70 anos).

"Tô com disposição pra mim andar, pra mim passear. Mais disposição pra trabalhar en tenho"(Idosa da comunidade, 77 anos).

Tão importante quanto as perdas dos laços familiares são as perdas físicas, especialmente a beleza, e sua conseqüência para a iden- 
tidade pessoal da idosa. O não-reconhecimento de sua própria imagem foi descrito por uma idosa institucionalizada, que mostra a dificuldade da aceitação das transformações físicas que ocorrem com o advento do envelhecimento:

"Eu tô muito acabada, quando eu olhei no espelho fiquei até triste, tô muito acabada. Feia que eu tô." (Idosa institucionalizada, 71 anos).

As ocupações e as preferências das idosas também estão muito influenciadas pelas questões culturais, que definem o que é mais adequado para ser realizado por mulheres. As idosas de nosso estudo apresentam preferências relacionadas à sua vida diária e a suas condições de vida e saúde. Dessa forma, as entrevistadas referem gostar mais das atividades domésticas:

"Ah, en gosto de fazer as coisas de casa. Arrumar casa, varrer casa, fazer comida, né." (Idosa institucionalizada, 88 anos).

"Gosto muito de mexer com bolo, com cozinha, cozinhar." (Idosa da comunidade, 70 anos).

As idosas que residem na comunidade apresentam maior diversidade de atividades, que são divididas entre as tarefas domésticas e interações sociais. Este grupo de idosas exibe certo nível de autonomia e independência, o que lhes garante a possibilidade de realizar tais atividades.

\section{CONSIDERAÇÕES FINAIS}

As idosas abordadas neste estudo apresentaram discursos e percepções que caracterizam a influência da institucionalização nas questões relacionadas ao próprio bem-estar. Apesar de ter sido abordado um pequeno número de sujeitos, e não ser objetivo do trabalho uma análise em expansão das questões, $\mathrm{e}$ sim em profundidade, alguns aspectos merecem ser destacados a partir deste estudo.

As idosas que residem na instituição atribuem ao trabalho o valor pessoal e o sentido da vida. A falta de atividades e a conseqüente inatividade levam essas mulheres a ficarem ociosas, vendo o tempo passar sem perspectivas e esperanças.

As institucionalizadas não apresentam interações sociais em seus discursos, o que provavelmente é responsável pela solidão e pelo sentimento de abandono implícito em suas falas. Neste ponto existe uma discrepância significativa entre os dois grupos de idosas. As que residem na comunidade deixam claro a presença de trocas realizadas com o "outro".

A percepção de doença está vinculada principalmente àquilo que as impede de realizar algum tipo de trabalho. Outra conotação para a doença é determinada pelas idosas.

O cuidado à saúde não é uma atitude autônoma entre as institucionalizadas, que delegam essa função à instituição onde residem.

As questões culturais, e sobretudo as religiosas, estão presentes entre todas as mulhe- 
res entrevistadas. A religião e a espiritualidade parecem garantir um sentido à vida e proporcionar um suporte emocional para as situações conflituosas advindas com o envelhecimento.

Diante de todos os aspectos analisados, podemos concluir que a institucionalização imprime nas idosas viúvas e de origem rural uma representação diferenciada em relação a seu próprio bem-estar. As questões que caracterizam o envelhecimento como uma fase de perdas, solidão e dependência estão presentes com maior intensidade entre as idosas que vivem na instituição asilar.

\section{NOTAS}

a Mestranda do Instituto Fernandes Figueira, Fundação Oswaldo Cruz, Rio de Janeiro, RJ, Brasil E-mail: adalpeixoto@yahoo.com.br

b Doutorando da Escola Nacional de Saúde Pública, Fundação Oswaldo Cruz, Rio de Janeiro, RJ, Brasil E-mail: gabo_ead@ensp.fiocruz.br

\section{REFERÊNCIAS}

1. Assis M. Envelhecimento e suas conseqüências. In: Caldas CP, organizadora. A saúde do idoso: a arte de cuidar.Rio de Janeiro: UnATI/UERJ; 1998. p.39-48.

2. Barros PMR, Oliveira MVC, Vasconcelos EMR. Política de atenção institucionalizada ao idoso. Anais do $50^{\circ}$ Congresso Brasileiro de Enfermagem; 1998 Set 20-25;. Salvador, BA: ABEn, s.d. p.128

3. Beauvoir S. A velhice: realidade incômoda. 2. ed. São Paulo: DIFEL; 1976.

4. Brito FC, Ramos LR. Serviços de atenção à saúde do idoso. In: Papaléo Neto M, organizador. Gerontologia: a velhice e o envelhecimento em visão globalizada. São Paulo: Atheneu; 1996.

5. Bulla LC, Mediondo MZ. Velhice, dependência e vida cotidiana institucional. In: Cortelletti IA, Casara MB, Herédia VM, organizadoras. Idoso asilado: um estudo gerontológico Caxias do Sul, RS: Educs/ Edipucrs; 2004, p. 87-107.

6. Capitanini MES, Neri AL. Sentimentos de solidão, bem-estar subjetivo e relações sociais em mulheres idosas vivendo sozinhas. In: Neri AL, Yassuda MS, organizadoras. Velhice bem-sucedida: aspectos afetivos e cognitivos. Campinas, SP: Papirus; 2004. p.71-90.

7. Davim RMB, et al. Estudo com idosos de instituições asilares no município de Natal/ $\mathrm{RN}$ : características socioeconômicas e de saúde. Rev Lat Am Enfermagem 2004; 12(3): 518-24.

8. Dorfman LT, et al. History and identity in the narratives of rural elders. J Aging Stud 2004; 18(2): 187-203.

9. Freire Jr RC. A saúde sob o olhar do idoso institucionalizado: conhecendo e valorizando suas opiniões. [monografia]. Rio de Janeiro: Escola Nacional de Saúde Pública, Fundação Oswaldo Cruz, 2003.

10. Herédia VM, Cortelletti IA, Casara MB. O asilamento sob o olhar de histórias de vida. In: Cortelletti IA, Casara MB, Herédia VM, organizadoras. Idoso asilado: um estudo gerontológico. Caxias do Sul, RS: Educs/ Edipucrs; 2004. p. 63-83.

11. Goldstein LLL. Stress e coping na vida adulta e velhice. In: Neri AL, organizadora. Psicologia do envelhecimento: temas selecionados na perspectiva de curso de vida. Campinas: Papirus; 1995. p. 145-58.

12. Minayo MCS. Saúde doença: uma concepção popular da etiologia. Cad Saúde Pública, 1988; 4(4): 363-81. 
13. Motta AB. Envelhecimento e sentimento do corpo. In: Minayo MCS, Coimbra Jr, organizadores. Antropologia, Saúde e Envelhecimento. Rio de Janeiro: Fiocruz; 2002. p. 37-50.

14. Parker C. Religião popular e modernização capitalista: uma lógica na América Latina. Petrópolis, RJ: Vozes, 1996.

15. Pietrukowicz MCLC. Apoio social e religião: uma forma de enfrentamento dos problemas de saúde. [dissertação]. Rio de Janeiro: Escola Nacional de Saúde Pública, Fundação Oswaldo Cruz, 2001.

16. Ramos MP. Social support and health among seniors. Sociologias 2002; 7: 156-75.

17. Rodrigues RAP, Marques S, Fabrício SCC. Envelhecimento, saúde e doença. Arquivos de geriatria e gerontologia 2000; 4(1): 15-20.

18. Ross L. The spiritual dimension: its importance to patients' health, well-being and quality of life and its implications for nursing practice. Int J Nurs Stud, 1995; 32 : 457-68.
19. Saxena S, O’Connell K, Underwood L. Cross-Cultural Quality-of-Life Assessment at the End of Life. Gerontologist 2002; 42: 81-5.

20. Siqueira RL, Botelho MIV, Coelho FMG. A velhice: algumas considerações teóricas e conceituais. Revista Ciência \& Saúde Coletiva 2002; 7(4): 899-906.

21. Valla VV. Redes sociais, poder e saúde à luz das classes populares numa conjuntura de crise. Interface 2000; 4(7): 37-56.

22. Veloz MCT, Nascimento-Schulze CM, Camargo BV. Representações sociais do envelhecimento. Psicologia, Reflexão e Critica 1999; 12(2): 479-501.

Recebido em: 14/9/2006

Aceito: 15/3/2007 
1 